\title{
Children's Normative Beliefs About Aggression and Aggressive Behavior
}

\author{
L. Rowell Huesmann \\ University of Michigan
}

\author{
Nancy G. Guerra \\ University of Illinois at Chicago
}

\begin{abstract}
Normative beliefs have been defined as self-regulating beliefs about the appropriateness of social behaviors. In 2 studies the authors revised their scale for assessing normative beliefs about aggression, found that it is reliable and valid for use with elementary school children, and investigated the longitudinal relation between normative beliefs about aggression and aggressive behavior in a large sample of elementary school children living in poor urban neighborhoods. Using data obtained in 2 waves of observations 1 year apart, the authors found that children tended to approve more of aggression as they grew older and that this increase appeared to be correlated with increases in aggressive behavior. More important, although individual differences in aggressive behavior predicted subsequent differences in normative beliefs in younger children, individual differences in aggressive behavior were predicted by preceding differences in normative beliefs in older children.
\end{abstract}

It has become increasingly clear that characteristic patterns of social behavior, and in particular aggressive behavior, emerge early in life. Past research has shown that, as early as at 12 months of age, children display behavioral styles that are more or less aggressive across a variety of situations (Holmberg, 1980; Kagen, 1988). By age 8, aggressiveness has become a relatively stable personality characteristic (Caspi, Elder, \& Bem, 1987; Eron \& Huesmann, 1990; Farrington, 1990; Huesmann, Eron, Lefkowitz, \& Walder, 1984; Loeber \& Dishion, 1983; Magnusson, Duner, \& Zetterblom, 1975; Moffitt, 1990; Olweus, 1979; Robins \& Ratcliff, 1980). Although there are differences of opinion concerning the causes of the statistical continuity of aggression in the population (see Moffitt, 1993), it is difficult to find any other childhood factor that predicts more of the variation in adult aggression than does childhood aggression.

Although aggression is highly stable, this does not imply that any single factor is responsible for such behavior. Rather, the literature strongly suggests that a multitude of factors contribute to an individual's propensity to behave aggressively. In particular, individual differences in aggressive behavior seem to be a product of the interaction of early predispositional factors with specific learning experiences (Berkowitz, 1993; Dodge, 1980;

L. Rowell Huesmann, Research Center for Group Dynamics, Institute for Social Research, University of Michigan; Nancy G. Guerra, Department of Psychology, University of Illinois at Chicago.

This research was supported by Grants MH-48034 and MH-47474 from the National Institute of Mental Health and Cooperative Agreement CCU510017 from the Centers for Disease Control and Prevention. A modified version of this article was presented at the American Psychological Society meeting in Chicago in June 1993. We would like to thank Sharon Grout and the staff of the Metropolitan Area Child Study project, who collected the data, and Ed Czilli, David Henry, and Christopher Maxwell for their contributions to the data analyses. Len Eron, Pat Tolan, and Rick VanAcker contributed to the conception of the studies. Correspondence concerning this article should be addressed to L. Rowell Huesmann. Research Center for Group Dynamics, Institute for Social Research, University of Michigan, Ann Arbor, Michigan 48106-1248. Electronic mail may be sent via the Internet to huesmann@umich.edu.
Eron, 1987; Geen, 1990; Huesmann, 1994; Huesmann \& Eron, 1989, 1992; Moffitt, 1993). Thus, characteristic patterns of aggressive behavior become more firmly established through a social learning process as the child develops into an adult.

Many recent learning theories of aggression have emphasized the central role of cognition in maintaining the stability of aggressive behavior over time and situations (Bandura, 1986; Berkowitz, 1988; Crick \& Dodge, 1994; Dodge, 1986; Huesmann, 1982,1988 ). A number of cognitive mechanisms have been delineated, and several empirical studies have demonstrated the relation of these cognitive mechanisms to aggressive behavior in both children and adolescents (Dodge, 1980, 1993; Guerra \& Slaby, 1990; Slaby \& Guerra, 1988). Many of these models and studies have focused on the role of specific cognitive information-processing skills or operations in the regulation of aggressive behavior.

Although this focus on information-processing operations and skills has provided a useful framework for an initial understanding of how characteristic styles of social behavior are established and maintained, it has only vaguely accounted for the role of organized prior knowledge in regulating such behavior. Furthermore, current reviews of social information-processing models of behavior such as that of Crick and Dodge (1994) have emphasized the role of both latent mental structures and on-line processing actions. A focus on latent mental structures is consistent with recent research in social psychology that has emphasized the importance of cognitive schemata, or abstracted general knowledge, in the regulation of behaviors, particularly automatic behaviors. From this perspective, social schemas reduce an individual's information-processing workload by simplifying reality, enabling individuals to function in a world that would otherwise be of paralyzing complexity (Abelson, 1981; Rumelhart \& Ortony, 1977). The schema concept has been applied to a range of social information, including information about the self, others, social roles, and events (Fiske \& Taylor, 1991 ).

Huesmann $(1982,1988$; Huesmann \& Eron, 1984) introduced the concept of one kind of cognitive schema, scripts, into the analysis of aggressive behavior. $\mathrm{He}$ argued that aggressive behavior is controlled to a great extent by scripts that are encoded, rehearsed, stored, and retrieved in much the same way as are 
scripts for intellectual behavior. The constancy of such scripts, once encoded, accounts to a great extent for the stability of aggression across time and situations.

According to this model (Huesmann, 1988), behaviors suggested by such scripts are filtered through self-regulating beliefs. Recently, we have identified a particular type of belief, which we refer to as a normative belief, that not only may play an important role in filtering out inappropriate behaviors, but also may affect emotional reactions to others' behaviors and may stimulate the use of appropriate scripts (Guerra, Huesmann, \& Hanish, 1994; Huesmann, Guerra, Miller, \& Zelli, 1992). By the term normative belief, we mean an individual's own cognition about the acceptability or unacceptability of a behavior. Normative beliefs serve to regulate corresponding actions by prescribing the range of allowable and prohibited behaviors. We have proposed that a broad spectrum of interpersonal actions fall under this type of normative regulation, from social conventional behaviors such as appropriate forms of addressing strangers to moral behaviors involving harm to others (Guerra, Huesmann, et al., 1994; Guerra, Nucci, \& Huesmann, 1994; Huesmann, Guerra, Miller, et al., 1992; Huesmann, Guerra, Zelli, \& Miller, 1992). Such beliefs may be situation specific or general. An example of a situation-specific normative belief would be "It's okay to hit others if they hit you first." An example of a general belief would be "It's okay to hit others."

Normative beliefs thus are defined as individualistic cognitive standards about the acceptability of a behavior. They should influence (and be influenced by) mental processing of events, but they are not the same. For example, as Crick and Dodge (1994) noted, response evaluation is part of an active response decision process that is driven partly by moral rules or values related to beliefs about the acceptability of a behavior. These mental structures constitute the database that influences an individual's on-line processing of social cues. Of course, other factors, such as affective states and recent stimulus cues, also may influence how normative beliefs are used in evaluating such a response.

Our model emphasizes a direct connection between children's cognitions about the appropriateness of behaviors (i.e., their normative beliefs) and the information-processing operations that culminate in the child's behavior. We propose that these beliefs influence responding in novel situations that require "controlled processing" as well as in familiar situations in which cognitive processing is more automatic (Schneider \& Shiffrin, 1977). Normative beliefs may or may not be consistent with the prevailing social norms, although there should be considerable overlap between an individual's normative beliefs and the normative beliefs of relevant peers, social groups, and societal institutions. We propose that these beliefs also serve to regulate behavior, regardless of whether they are backed by internal or external sanctions, although beliefs that are supported by internalized sanctions should be more stable and more resistant to situational influences. Defined in this manner, normative beliefs are not hard to measure, even in young children (Huesmann, Guerra, Miller, et al., 1992; Huesmann, Guerra, Zelli, et al., 1992).

Several predictions derive from this line of thinking. Of course, people who are more aggressive should have normative beliefs that are more approving of aggression. In addition, over time those people with stronger approval-of-aggression norma- tive beliefs should become more aggressive. However, particularly with children, it also may be true that engaging in aggressive behavior promotes the development of normative beliefs approving of aggression as emerging mental structures and online processing exert a reciprocal influence. In any case, one would expect young children to have less stable beliefs than older children. Consistent with age and gender differences in aggression (e.g., Guerra, Huesmann, Tolan, Van Acker, \& Eron, 1995), one would expect older children and boys to have beliefs that are more accepting of aggression, although gender differences in endorsement of aggression may parallel gender differences in specific types of aggression most frequently displayed by boys or girls (e.g., Bjorkqvist, Lagerspetz, \& Kaukiainen, 1992; Crick \& Grotpeter, 1995). Nevertheless, with different types of aggression (e.g., direct vs. indirect), relations between normative beliefs about that type of aggression and corresponding behaviors should be maintained for both genders.

In our own recent studies with children (Huesmann, Guerra, Miller, et al., 1992; Huesmann, Guerra, Zelli, et al., 1992) and with adolescents (Slaby \& Guerra, 1988), we found a weak but significant relation between acceptance of aggression and aggressive and delinquent behavior. In those studies, there also was a tendency for these relations to be greater among older children. However, the results were not strong, and we did not have sufficient longitudinal data to examine adequately developmental trends and causal models for relations between aggression and beliefs over time. Furthermore, the 35 -item belief questionnaire used in the study with children was too long for young children and seemed to be measuring more than normative beliefs. The questions assessing what we have now defined as individual normative beliefs were mixed with questions assessing perceived social norms of adults for children's behavior.

In the current studies, we revised our scale for assessing normative beliefs about aggression, found that it is reliable and valid for use with elementary school children, and investigated the longitudinal relation between normative beliefs about aggression and aggressive behavior using two waves of data from a large sample of elementary school children living in poor urban neighborhoods. Although these neighborhoods are often characterized by high rates of youth violence (Fingerhut \& Kleinman, 1990; Hammond \& Yung, 1991) and are often described as including subcultural groups who follow a "code of violence"' (Anderson, 1990), little empirical research has been conducted within this setting to examine how children's aggressive behavior varies as a function of their individual beliefs about the appropriateness of such behavior and whether these relations vary by gender and age.

\section{Study 1}

In Study 1, we derived a revised form of the Normative Beliefs About Aggression Scale (NOBAGS) that is appropriate for elementary school children. We found that it is reliable for a range of ages, for both genders, and across ethnic groups. As predicted, normative beliefs about aggression increased in stability with age. Finally, normative beliefs about both retaliatory aggression and general aggression correlated with aggressive behavior, particularly in boys. 


\section{Method}

\section{Participants}

The participants for this study constituted the initial sample of a largescale assessment and intervention study, the Metropolitan Area Child Study (MACS). This study was conducted in lower income neighborhoods of two midwestern cities, one large city and one midsized city located approximately $\mathbf{4 0}$ miles from the large city. All participants were selected through a school recruitment process based on the school's willingness to participate in both the assessment and intervention phases of the study. The 16 schools originally selected for participation constituted those volunteering schools in low socioeconomic, high-crime neighborhoods who would best contribute to an ethnically diverse sample. Parent permission was obtained through a multistep procedure. Using this procedure we were able to obtain an overall permission rate of $86.6 \%$, resulting in an initial sample of 1,550 first-grade $(n=784)$ and fourth-grade $(n=766)$ children. These children were predominantly African American (38.3\%), Hispanic (36.6\%), or White $(18.1 \%)$. The sample was about evenly split between boys (48\%) and girls (52\%). The proportion of children receiving federally subsidized free lunches in these schools ranged from $25 \%$ to $82 \%$, indicating substantial poverty within the sample. For a more detailed description of participant selection and sample characteristics, see Guerra et al. (1995).

Data were collected on this sample at three time points. The initial data on normative beliefs used for reliability analyses were collected in the spring of 1991 from all 1,550 children. Data for the validity analysis were collected in the fall of 1991 at the beginning of the next school year on the 1,070 children who remained.' Data for the 1-year stability analyses were collected in the spring of 1992 on 846 of the 1,070 children $(80 \%)$ who remained in the same schools and were present at the reassessment sessions.

\section{Measures}

Revised normative beliefs measure. When we began our initial investigation of normative beliefs (Huesmann, Guerra, Miller, et al., 1992; Huesmann, Guerra, Zelli, et al., 1992), we recognized a number of the difficult measurement problems inherent in any attempt to assess children's beliefs about the acceptability of aggressive behaviors. Children's reports could be expected to be highly sensitive to the demand characteristics of the questioning and to the perceived social desirability of the possible responses. Children's beliefs could be expected to change radically with age, and young children might not have any stable beliefs of their own and might simply respond to situational cues.

In those initial studies (Huesmann, Guerra, Miller, et al., 1992; Huesmann, Guerra, Zelli, et al., 1992), we derived a 35-item scale for assessing beliefs about the approval of aggression. Beginning with the conception that beliefs about aggression are cognitions about the acceptability of specific aggressive behaviors in specific contexts, we had developed a set of 88 questions that might be appropriate for elementary school children. Taking Fishbein and Ajzen's (1975) categorization of social behaviors on the basis of "action, target, context, and time" as a point of departure, we described aggressive acts that varied in characteristics of actor, target, and provocation. Specifically, these items varied on four dimensions: severity of provocation, severity of response, gender of provoker, and gender of responder. The questions followed a format that Guerra and Slaby (1990; Slaby \& Guerra, 1988) had developed and asked children, "How often do you think ____ is okay: never, sometimes, often, or always." For example, one question was "It's okay for a boy, Tom, to hit a girl, Julie, if Julie says something bad to Tom first." The strong-weak provocation manipulation was accomplished by substituting "if Julie hits" for "if Julie says something bad to." Similarly, the severity of response manipulation was accomplished by changing "It's okay for for to scream at
In the scale's first version, questions were included to assess not only whether children thought a behavior was acceptable but whether they thought other children and other adults would think it was acceptable (similar to our notion of perceived social norms). However, our results revealed that it did not matter whether one asked a child about whether the child thought the behavior was okay or asked the child about whether most children thought the behavior was okay. If a child believed most children thought it was okay, the child thought it was okay himself or herself. In other words, the children's normative beliefs were highly correlated with their perceptions of children's social norms. During the process of scale refinement in these studies, these items were deleted along with other items that had low item-total correlations.

The final 35-item scale derived in these studies was tested on a sample of 293 inner-city, mostly minority second- through fourth-grade children. The results revealed that one could reliably assess individual differences in normative beliefs on a variety of subscales with these questions (Huesmann, Guerra, Miller, et al., 1992; Huesmann, Guerra, Zelli, et al., 1992). These included Overall Approval of Aggression at Children ( $\alpha$ $=.90)$, Aggression at Boys $(\alpha=.83)$, Aggression at Girls $(\alpha=.84)$, Aggression Under Weak Provocation $(\alpha=.80)$, and Aggression Under Strong Provocation $(\alpha=.84)$. The 3-month stability of scores on the Overall Aggression at Children scale was .48, with the stabilities on the subscales ranging from .36 to .47 . The children's scores on many of these preliminary scales also correlated very significantly with their selfreports of aggressive behavior for both boys and girls and significantly with peer nominations of aggressive behavior for boys.

Although the results of these initial studies demonstrated that children's approval of aggression could be measured reliably, they also suggested that the scale would benefit from further refinement. The correlations with actual aggressive behavior were not very significant except when the aggressive behavior was also measured by self-reports. The differences one might expect as a function of age and gender were not large, and the questionnaire was long for use with early elementary school children. Finally, the questionnaire seemed to be measuring more than one belief structure. Questions assessing what we have now defined as personal normative beliefs were mixed with questions assessing perceived social norms for adults.

On the basis of these considerations, we created a revised 20 -item scale directed at assessing children's normative beliefs as concisely as possible. The 20 -item scale included 12 of the 35 items from the original scale and retrained the subscale structure for retaliation questions of weak versus strong provocation and aggression at boys versus aggression at girls. We eliminated the questions that did not fit theoretically with our conception of normative beliefs (e.g., questions about adult beliefs), questions that did not increase the internal consistency of the scale they were on because they had little variance (e.g., "It's okay to scream at someone after being hit"), and questions that correlated highly with other questions and did not explain any unique variance of relevance (e.g., questions with "out of control" as the provocation). Equally important, to tap the more general normative beliefs about aggression, we added eight questions that did not include any provocation but simply asked the child if it was generally okay to use aggression (e.g., "It is usually okay to push and shove other people around if you're mad"). The resulting 20 items are listed in the Appendix.

It is worth noting that in our initial studies with the 35 -item scale, we had tested forms of each question with the order and direction of the response choices reversed. We found no difference between the

\footnotetext{
'Shortly after the initial assessment of normative beliefs, in the spring of 1991, two schools with 218 first and fourth graders dropped out of the study. In addition, over the summer of 1991, 262 children moved, changed schools, or failed a grade, leaving 1,070 of the original first and fourth graders on the second- and fifth-grade class lists in the fall of $1992(70 \%)$. These remaining 1,070 children constituted the sample for the validity analyses.
} 
forms, which suggests that positive response bias by more aggressive participants was not a problem. Nevertheless, half of the questions on the final form were worded in the positive ("OK") direction and half in the negative ("wrong") direction to control for any such effect.

Aggression measures. The Peer-Nominated Index of Aggression (Eron, Walder, \& Lefkowitz, 1972) was used to obtain a measure of each child's aggression. The methodology that we used to obtain peernominated scores for a child has been used for more than 30 years with demonstrated reliability and validity in several cultures (Huesmann \& Eron, 1986). In this procedure, each child is presented with a printed page with a list of all boys and girls in his or her classroom, with the names grouped by gender. The child is asked to circle every name that fits the question at the top of the page (e.g., "Who pushes and shoves other children?'). The questions assess physical aggression, verbal aggression, and indirect aggression (e.g., "Who makes up stories and lies to get others in trouble?"). The experimenter paces the children so that exactly the same amount of time is spent on each question. A child's score on a scale is derived by taking the number of times the child is nominated by other children on questions that fall on that scale and dividing by the total number of times the child could have been nominated. By this definition peer-nominated scores range from 0 to 1 .

The teachers also rated all participants on the Child Behavior Checklist (CBCL; Achenbach, 1978, 1991). This reliable and well-validated measure contains a list of 118 behavior problem items that the teacher rates on a 3-point scale. In this study we analyzed only the 39-item Aggression scale of the checklist.

\section{Procedure}

The measures were administered individually for children in the first grade and were administered in the child's regular school classroom for children in the remaining grades. In all cases, the experimenter read the questions aloud for each measure. For classroom administration, at least one other assistant was present during administration to monitor the children. In classrooms with Spanish-speaking children, measures that had been translated and back-translated were provided, and children were permitted to choose the language of testing. At least one Spanishspeaking experimenter was present. No difficulties in understanding the items were noted.

\section{Results}

The reliabilities of the total score and six subscales on the revised NOBAGS (Normative Beliefs About Aggression Scale) are shown in Table 1 . One can see that not only does the overall scale and each subscale have substantial internal reliability within the whole sample, but the reliability holds up within both genders, within all three ethnic groups, and for both first and fourth graders. It seems clear that the revised questionnaire, although much shorter than the original questionnaire, is still a highly reliable measurement tool.

Given that these children's normative beliefs could be reliably measured, we examined the relation between these beliefs and actual behavior. In Table 2 the correlations are presented between the two aggression measures and the normative beliefs scale for the validity subsample of 1,070 children. The Total Approval of Aggression scale, the General Approval of Aggression scale, the Approval of Retaliation scale, and the four subscales for retaliation all correlated significantly both with peer nominations of aggression and with teacher ratings of aggression. The correlations were significantly greater, Williams $t(995)>18, p \mathrm{~s}<.001$, for every case, between beliefs and the peer nominations of aggression than between beliefs and the teacher ratings. The correlations were not high by the standards of adult personality research, but they were consistently significant and substantial by the standards of children's personality measurement.

Figure 1 illustrates the meaning of these correlations between the normative beliefs scales and peer-nominated aggressive behavior. In each graph in the figure, the mean aggression score is plotted for children who scored in the upper quartile, the middle $50 \%$, or the lower quartile on the Specific Approval of Aggression scale. One can see that those who score in the upper quartiles are particularly at risk for aggressive behavior. For example, those scoring in the upper quartile on the Total Approval of Retaliation scale were about 0.25 standard deviations higher on aggressive behavior than the middle group. This is not a large effect size, but it is big enough to be socially significant, as Rosenthal (1986) persuasively argued.

In Table 3 the correlations between the normative beliefs scales and the stronger correlate, peer-nominated aggression, are broken down by gender, ethnic group, and grade. The correlations between beliefs and aggression were highly similar for first and fourth graders; however, the correlations between beliefs and aggression for girls were consistently lower than for boys ( significantly lower for the overall score, $z=2.32, p<$

Table 1

Reliabilities (Cronbach's Alphas) of Normative Beliefs About Aggression Scale and Subscales

\begin{tabular}{|c|c|c|c|c|c|c|c|c|c|}
\hline \multirow[b]{3}{*}{ Scale } & \multirow[b]{3}{*}{ Items } & \multirow[b]{3}{*}{$\begin{array}{c}\text { Overall } \\
(N=1,550)\end{array}$} & \multirow{2}{*}{\multicolumn{2}{|c|}{ Gender }} & \multicolumn{3}{|c|}{ Ethnicity } & \multirow{2}{*}{\multicolumn{2}{|c|}{ Grade }} \\
\hline & & & & & \multirow{2}{*}{$\begin{array}{l}\text { African } \\
\text { American } \\
(n=602)\end{array}$} & \multirow[b]{2}{*}{$\begin{array}{c}\text { White } \\
(n=280)\end{array}$} & \multirow[b]{2}{*}{$\begin{array}{l}\text { Hispanic } \\
(n=567)\end{array}$} & & \\
\hline & & & $\begin{array}{c}\text { Female } \\
(n=806)\end{array}$ & $\begin{array}{c}\text { Male } \\
(n=744)\end{array}$ & & & & $\begin{array}{c}\text { First } \\
(n=784)\end{array}$ & $\begin{array}{l}\text { Fourth } \\
(n=766)\end{array}$ \\
\hline Total Approval of Aggression & $1-20$ & .86 & .86 & .86 & .84 & .90 & .86 & .87 & .84 \\
\hline General Approval of Aggression & $13-20$ & .80 & .79 & .80 & .80 & .83 & .79 & .78 & .82 \\
\hline Approval of Retaliation & $1-12$ & .82 & .83 & .80 & .80 & .85 & .81 & .82 & .77 \\
\hline $\begin{array}{l}\text { Approval of Retaliation, } \\
\text { Weak Provocation } \\
\text { Approval of Retaliation, }\end{array}$ & $1-8$ & .75 & .76 & .74 & .71 & .79 & .75 & .75 & .71 \\
\hline $\begin{array}{l}\text { Strong Provocation } \\
\text { Approval of Retaliation Against }\end{array}$ & $9-12$ & .71 & .75 & .68 & .72 & .76 & .64 & .71 & .65 \\
\hline $\begin{array}{l}\text { Males } \\
\text { Approval of Retaliation Against }\end{array}$ & $1-4,9,10$ & .70 & .73 & .67 & .66 & .74 & .70 & 65 & .65 \\
\hline Females & $5-8,11,12$ & .69 & .70 & .68 & .67 & .76 & .68 & .71 & .65 \\
\hline
\end{tabular}


Table 2

Correlations of Normative Beliefs About Aggression With Aggressive Behavior for Complete-Data Children $(N=1,015)$

\begin{tabular}{lcc}
\hline \multicolumn{1}{c}{ Seale } & $\begin{array}{c}\text { Peer-nominated } \\
\text { aggression }\end{array}$ & $\begin{array}{c}\text { Teacher-rated } \\
\text { CBC aggression }\end{array}$ \\
\hline Total Approval of Aggression & $.23^{* * *}$ & $.10^{* *}$ \\
General Approval of Aggression & $.18^{* * *}$ & $.08^{*}$ \\
Approval of Retaliation & $.21^{* * *}$ & $.10^{* *}$ \\
Approval of Retaliation, Weak Provocation & $.21^{* * * *}$ & $.10^{* *}$ \\
Approval of Retaliation, Strong Provocation & $.16^{* * *}$ & $.07^{*}$ \\
Approval of Retaliation Against Males & $.22^{* * *}$ & $.12^{* * *}$ \\
Approval of Retaliation Against Females & $.16^{* * * *}$ & $.06^{*}$ \\
\hline
\end{tabular}

Nore. $\quad$ CBC $=$ Child Behavior Checklist.

${ }^{*} p<.05 .{ }^{* *} p<.01 .{ }^{* * *} p<.001$.

.01 , one-tailed, and for all the subscales, $z>1.65, p<.05$, one-tailed, except strong provocation ). With regard to ethnicity, beliefs generally correlated slightly higher with aggression for Hispanic children and lower for non-Hispanic White children, but none of these differences were significant.

The stabilities of the NOBAGS subscales were next estimated from the stability subsample. These were the children in the 14 schools who continued in the study and who could be located and tested 1 year after their first testing $(n=846)$. In Table 4 the stabilities of these children's scores on the normative beliefs scales are displayed over the course of a year from one spring to the next. Although the stabilities were not high, they were significant statistically and meaningful, particularly considering the age of the children. However, the scores on the General Beliefs subscale showed significantly less stability over 1 year than any of the others (Pearson-Fillon $z>1.91, p<.056$, twotailed, for General Beliefs vs. Retaliation Against Females; $z>$ $1.95, p<.05$, for all others ).

A notable result in these stability data is the consistently lower stability over time of the younger children's normative beliefs. We had predicted that for younger children, normative beliefs would be in a more formative stage and would not appear

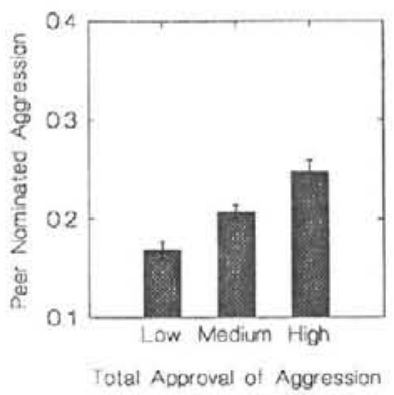

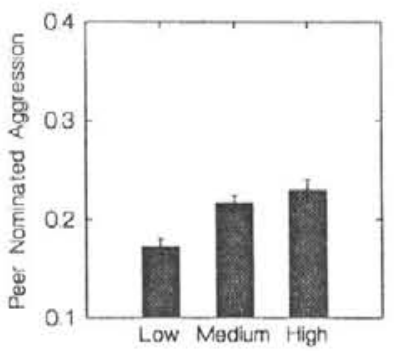

General Approval of Aggression

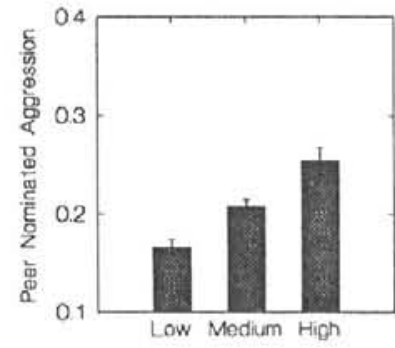

Approvel of Retaliation
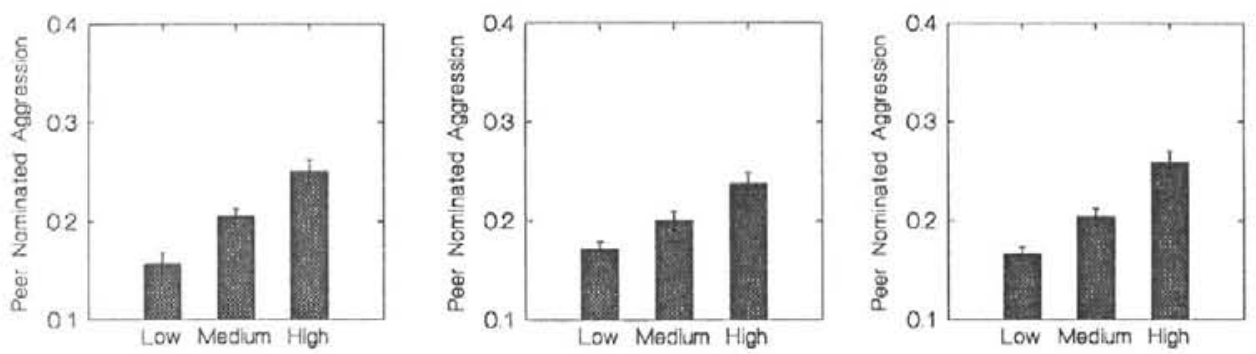

Approval of Retaliation Weak Provocation Approval of Retallation Strong Provocatlon Approval of Retaliation Against Males

Approval of Rataliation Weak Provocation Approval of Petallation Strong Provocation Approval of Rataliation Against Males

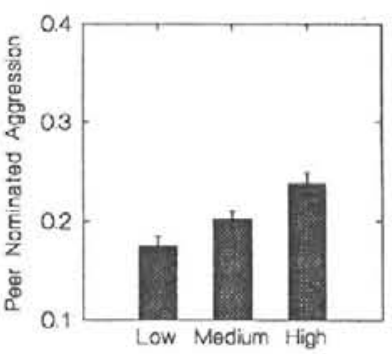

Approval of Retaliation Against Females

Figure 1. The relation between normative beliefs about aggression and peer-nominated aggressive behavior for 1,015 elementary school children. The low-, medium-, and high-aggression groups represent approximately the kwest quartile, the middle $50 \%$, and the upper quartile. respectively. 
Table 3

Correlations of Normative Beliefs About Aggression With Peer-Nominated Aggression by Gender, Ethnicity, and Grade

\begin{tabular}{|c|c|c|c|c|c|c|c|c|}
\hline \multirow[b]{3}{*}{ Scale } & \multirow[b]{3}{*}{$\begin{array}{c}\text { Overall } \\
(N=1,030)\end{array}$} & \multirow{2}{*}{\multicolumn{2}{|c|}{ Gender }} & \multicolumn{3}{|c|}{ Ethnicity } & \multirow{2}{*}{\multicolumn{2}{|c|}{ Grade }} \\
\hline & & & & & & & & \\
\hline & & $\begin{array}{c}\text { Female } \\
(n=546)\end{array}$ & $\begin{array}{c}\text { Male } \\
(n=484)\end{array}$ & $\begin{array}{l}\text { American } \\
(n=414)\end{array}$ & $\begin{array}{c}\text { White } \\
(n=187)\end{array}$ & $\begin{array}{l}\text { Hispanic } \\
(n=429)\end{array}$ & $\begin{array}{c}\text { First } \\
(n=515)\end{array}$ & $\begin{array}{c}\text { Fourth } \\
(n=515)\end{array}$ \\
\hline Total Approval of Aggression & $.22 * * *$ & $.12 * *$ & $.26 * * *$ & $.18^{* * *}$ & .14 & $.25^{* * *}$ & $.17 * * *$ & $.18 * * *$ \\
\hline General Approval of Aggression & $.17^{* * *}$ & .08 & $.19^{* * *}$ & $.15^{* *}$ & .14 & $.22 * * *$ & $.14^{* *}$ & $18^{* * *}$ \\
\hline Approval of Retaliation & $.20^{* * *}$ & $.12 * *$ & $.25 * * *$ & $.17^{* *}$ & .13 & $.22 * * *$ & $.16^{* * *}$ & $.15 * *$ \\
\hline Approval of Retaliation, Weak Provocation & $.20 * * *$ & $.11^{* *}$ & $.24 * * *$ & $.19 * * *$ & .12 & $.24 * * *$ & $.17 * * *$ & $.15 * *$ \\
\hline Approval of Retaliation, Strong Provocation & $.15^{* * *}$ & $.10^{*}$ & $.18 * * *$ & .09 & .11 & $.15^{* *}$ & $.10^{*}$ & $.10^{*}$ \\
\hline Approval of Retaliation Against Males & $.21 * * *$ & $.15 * *$ & $.27 * * *$ & $.17 * *$. & .13 & $.25 * * *$ & $.18 * * *$ & $.15 * *$ \\
\hline Approval of Retaliation Against Females & $.15 * * *$ & .06 & $.17 * * *$ & $.13 * *$ & .10 & $.16^{* *}$ & $.11^{*}$ & $.11^{*}$ \\
\hline
\end{tabular}

Note. Children in other ethnic groups $(n=40)$ were not included in correlations.

${ }^{*} p<.05 .{ }^{* *} p<.01 .{ }^{* * *} p<.001$.

as stable as for older children. That prediction was confirmed because the stability of total beliefs $(z=4.24, p<.001)$ and of every subscale $(z>4, p<.001)$ except General Beliefs was significantly higher for fourth graders than for first graders. Given that the internal consistencies of the scales were not lower for the younger than the older children, the higher stabilities for older children must reflect a greater stability in true scores.

\section{Study 2}

In Study 1 we found that the revised NOBAGS and its subscales are reliable and valid measures of normative beliefs about aggression for early elementary school children in urban settings. Most normative beliefs about aggression do correlate with actual aggressive behavior, but less so for girls than for boys. The correlations with aggressive behavior do not vary significantly between ethnic groups or between first and fourth graders, although the stability of beliefs is certainly lower for first graders.

In Study 2 we expanded our examination of the relation between normative beliefs about aggression and actual behavior by collecting longitudinal developmental data on normative beliefs and aggressive behavior. Using data obtained in two waves of observations 1 year apart, we found that children tended to approve more of aggression as they grew older and that this increase appeared to be correlated with an increase in aggressive behavior. More important, we found that although individual differences in aggressive behavior predicted subsequent differences in normative beliefs in younger children, individual differences in aggressive behavior were predicted by preceding differences in normative beliefs in older children.

\section{Method}

\section{Participants}

The longitudinal sample for Study 2 consisted of 1,015 inner-city children who were in the second $(n=317)$, third $(n=323)$, and fifth $(n=375)$ grades in the fall of 1991 . There were 503 girls and 512 boys in the sample. In discussing the results, we refer to these subsamples as Cohorts 2,3 , and 5 , respectively, after the grade they were in during the 1991-1992 school year. These children came from the 14 schools used for the stability analysis in Study 1 and two comparable schools added to replace the two schools that had dropped out of Study 1 after the 1990-1991 school year. There were 1,935 children in these grades in the schools, for whom permission was obtained. The longitudinal sample of 1,015 was the subset of the children who stayed in school

Table 4

Stabilities of Normative Beliefs About Aggression Scale and Subscales

1-year stabilities (Waves 1 and 2)

\begin{tabular}{|c|c|c|c|c|c|c|c|c|}
\hline \multirow[b]{4}{*}{ Scale } & \multirow[b]{4}{*}{$\begin{array}{c}\text { Overall } \\
(N=846)\end{array}$} & \\
\hline & & \multirow{2}{*}{\multicolumn{2}{|c|}{ Gender }} & \multicolumn{3}{|c|}{ Ethnicity } & \multirow{2}{*}{\multicolumn{2}{|c|}{ Grade }} \\
\hline & & & & & & & & \\
\hline & & $\begin{array}{c}\text { Female } \\
(n=441)\end{array}$ & $\begin{array}{c}\text { Male } \\
(n=405)\end{array}$ & $\begin{array}{l}\text { American } \\
(n=327)\end{array}$ & $\begin{array}{c}\text { White } \\
(n=162)\end{array}$ & $\begin{array}{c}\text { Hispanic } \\
(n=357)\end{array}$ & $\begin{array}{c}\text { First } \\
(n=402)\end{array}$ & $\begin{array}{c}\text { Fourth } \\
(n=444)\end{array}$ \\
\hline Total Approval of Aggression & $.31 * * *$ & $.29 * * *$ & $.30^{* * *}$ & $.27 * * *$ & $.25 * *$ & $.36 * * *$ & $.13^{* *}$ & $.40 * * *$ \\
\hline General Approval of Aggression & $.20^{* * *}$ & $.24 * * *$ & .13 & .12 & .11 & $.29 * * *$ & $.19^{* * *}$ & $.21 * * *$ \\
\hline Approval of Retaliation & $.34 * * *$ & $.32 * * *$ & $.35 * * *$ & $.32 * * *$ & $.29 * * *$ & $.37 * * *$ & $.10^{*}$ & $.44^{* * *}$ \\
\hline Approval of Retaliation, Weak Provocation & $.28 * * *$ & $.23 * * *$ & $.30^{* * *}$ & $.29 * * *$ & $.22 * *$ & $.29 * * *$ & .07 & $.37 * * *$ \\
\hline Approval of Retaliation, Strong Provocation & $.32^{* * *}$ & $.34 * * *$ & $.30^{* * *}$ & $.26 * * *$ & $.32 * * *$ & $.34 * * *$ & $.11^{*}$ & $.38 * * *$ \\
\hline Approval of Retaliation Against Males & $.35 * * *$ & $.34 * * *$ & $.36 * * *$ & $.33 * * *$ & $.32 * * *$ & $.37^{* * *}$ & $.14 * *$ & $.42 * * *$ \\
\hline Approval of Retaliation Against Females & $.27^{* * *}$ & $.22 * * *$ & $.28 * * *$ & $.25^{* * *}$ & $.22^{* *}$ & $.30^{* * *}$ & .06 & $.36^{* * * *}$ \\
\hline
\end{tabular}

${ }^{*} p<.05 . \quad{ }^{*} p<<.01 . \quad * * * p<.001$. 
until June 1993 and on whom three waves of data on normative beliefs and two waves of data on peer-nominated aggression were obtained between April 1991 and June 1993. Given that the schools were in highmobility urban neighborhoods and that data had to be contributed at three time points over a 2 -year period for a child to remain in the sample, the sampling rate of $53 \%$ is comparable to that obtained in similar studies. As shown in Guerra et al. (1995), the participants who dropped out were slightly more aggressive on average than the retained participants. Such differential dropout (which is typical of aggression studies) might reduce the obtained effect sizes of relations to aggression, but it will not affect the Type I error rate for the hypotheses tested about aggression.

\section{Procedure}

For Cohorts 2, 3, and 5 in the 14 original schools, Wave 1 data on aggression were collected during the spring of the 1990-1991 school year when children were finishing the first, second, and fourth grades, respectively. Wave 1 data on normative beliefs were collected for Cohorts 2 and 5 in these schools at the same time. However, Wave 1 data on normative beliefs were collected for Cohort 3 at the start of their thirdgrade year in the fall of the 1991-1992 school year. Similarly, all Wave 1 data for the children in the two new schools (Cohorts 2,3, and 5) were collected in the fall of the 1991-1992 school year. During Wave 2 only normative beliefs data were collected. Wave 2 data were collected for all children in Cohorts 2, 3, and 5 in all schools in the spring of the 1991-1992 school year when they were finishing the second, third, and fifth grades, respectively. During Wave 3 both normative beliefs data and peer nominations of aggression were collected again. Wave 3 data were collected for all children in Cohorts 2, 3, and 5 in all schools in the spring of the 1992-1993 school year when they were finishing the third, fourth, and sixth grades, respectively. The measures and data collection procedures were identical to those used in Study 1.

\section{Results}

We first examined how the mean score obtained on the NOBAGS Total Approval of Aggression scale varied with gender and age. In Figure 2 the means are plotted separately for boys and girls in each cohort at each of the three measurement points. Boys approved of aggression more than girls in every cohort and grade. For both genders, approval of aggression increased steadily with grade, but it particularly increased between first and second grade. The age trends and gender differences shown in Figure 2 were statistically significant. A multivariate repeated measures analysis of variance revealed significant gender effects, $F(1,1009)=80.5, p<.001$, significant cohort effects, $F(2,1009)=50.2, p<.001$, significant grade effects within cohort, $F(2,1008)=33.3, p<.001$, and a significant Cohort $\times$ Grade interaction, $F(4,2016)=4.89, p<.001$, with a significant quadratic trend, $F(2,1009)=7.94, p<.001$, caused by the large increase from first grade to second grade in Cohort 2.

Next, using this longitudinal sample, we investigated the relation of normative beliefs to aggression and of aggression to normative beliefs over time. Although beliefs were measured at three points in time (1991, 1992, and 1993), the first two measurements were separated by only 6 months for about one third of the participants, as described earlier. In addition, aggression was measured only at two points: spring 1991 and spring 1993. Therefore, we combined the first two measurements of normative beliefs by taking an average and analyzed the data as a two-wave panel design using the combined measure as a predictor variable for aggression.

Using multiple regression equations (see Figure 3), we compared how well one could predict Wave 3 aggression from earlier normative beliefs and aggression with how well one could predict Wave 3 normative beliefs from earlier normative beliefs and aggression. These regressions were conducted separately for each cohort with gender included in the models. Although the mean scores for girls on beliefs and aggression were lower, and, as Study 1 showed, the correlations for girls between beliefs and aggression were lower, the direction of the correlations was the same for both genders. When we first tested the basic regression model predicting change in aggression from earlier aggression and normative beliefs for all participants combined, we found a significant cohort effect $(p<.04)$ and a suggestion of a Cohort $\times$ Beliefs interaction $(p<.15)$, but no hint of a gender effect $(p>3)$ or a Gender $\times$ Beliefs interaction $(p>.5)$. Furthermore, separate gender regressions did not produce a single significantly different regression coefticient for boys and girls. Therefore, we combined genders and conducted the regressions separately by cohort. 2nd Grade Cohort

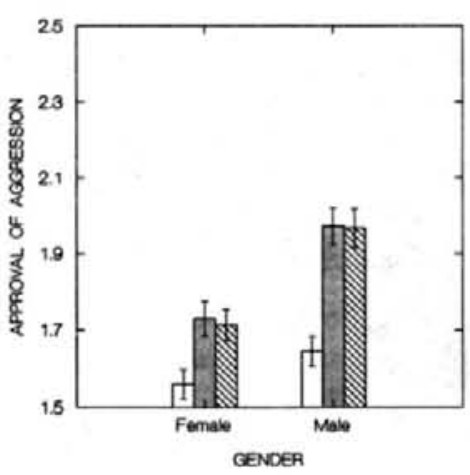

3rd Grade Cohort
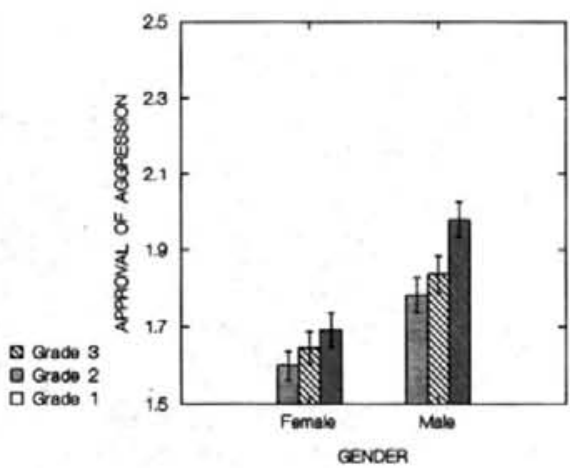
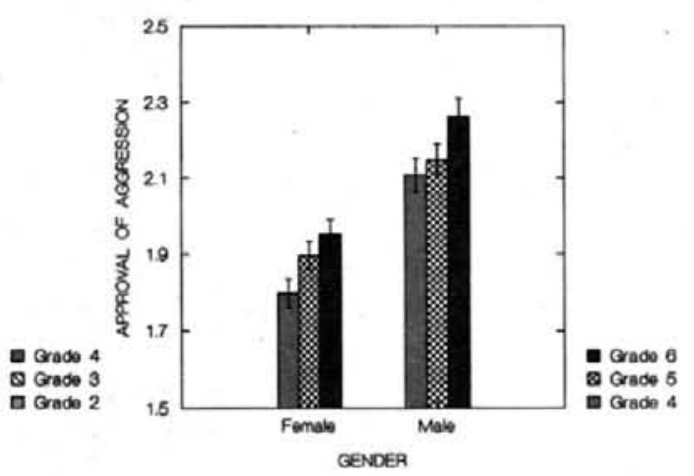

Figure 2. Developmental trends in normative beliefs for second-grade $(n=317)$, third-grade $(n=323)$, and fifth-grade $(n=375)$ cohorts of children. 


\section{2nd GRADE COHORT}

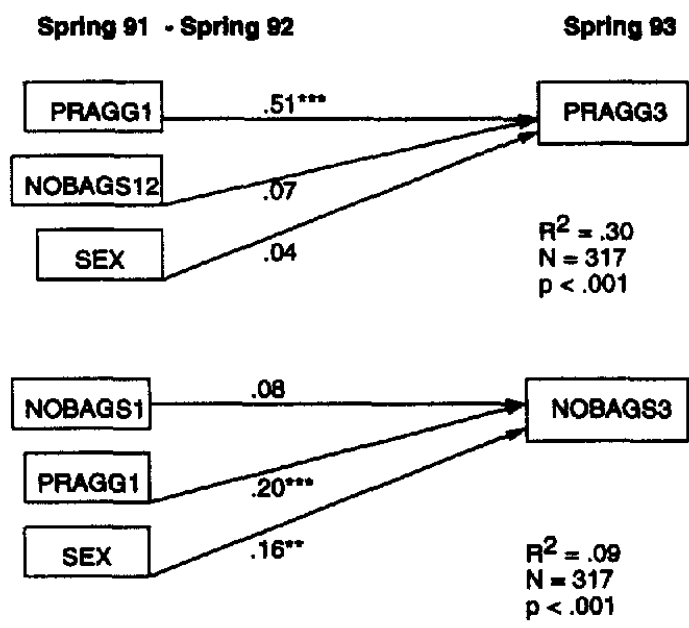

3rd GRADE COHORT
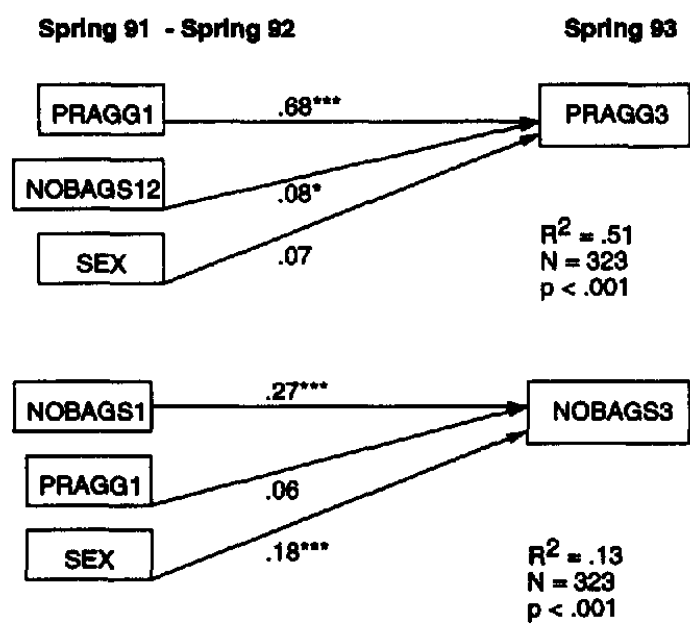

Sth CRADE COHORT

Spring 81 - Spring 92

Spring 93
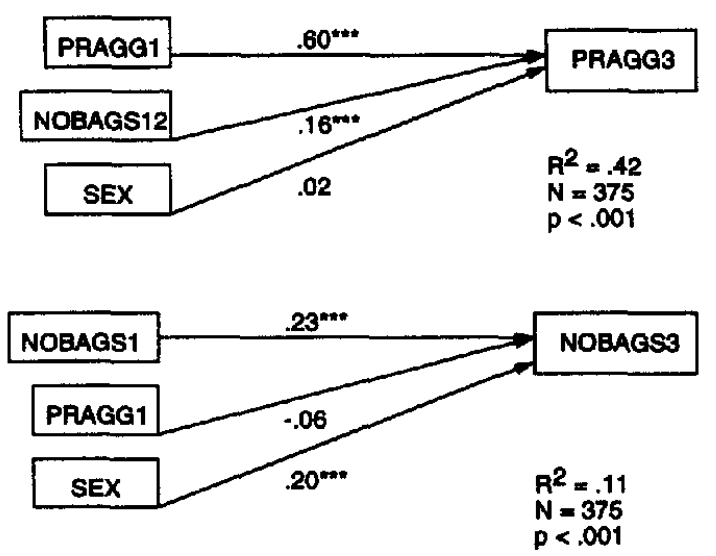

In Figure 3 the results of these regression analyses are diagrammed separately for Cohorts 2,3 , and 5 . These regressions revealed substantial cohort differences and are illuminating. For the youngest children, as one would expect from Study 1, there was little stability in normative beliefs about aggression, and initial normative beliefs were not good predictors of later normative beliefs. Nor did early normative beliefs add at all to the prediction of later aggression for these young children. However, a young child's level of early aggressive behavior was a significant predictor of the child's later normative beliefs about aggres$\operatorname{sion}(\beta=.20, p<.001)$. In other words, aggressive behavior on the part of these young children seemed to increase their own approval of aggression, but their approval or lack of approval of aggression did not influence their behavior much.

As the children grew older, however, the situation changed. For Cohort 3 , as these regressions show, normative beliefs became more stable, that is, predictable from initial normative beliefs $(\beta=.27, p<.001$, vs. $\beta=.08, n s$, for Cohort 2$)$, $t(633)=2.19, p<.03$, for difference. Normative beliefs also were no longer predictable from previous aggressive behavior $(\beta=.06, n s$, vs. $\beta=.20, p<.001$, for Cohort 2$), t(633)=$ $2.41, p<.02$, for difference. At the same time, normative beliefs began to significantly predict individual differences in aggressive behavior $(\beta=.08, p<.05)$. For children in the fifth-grade cohort, the change was pronounced. Normative beliefs now were a highly significant predictor over time of changes in aggressive behavior $(\beta=.16, p<.001$, vs. $\beta=.07, n s$, and $\beta=.08, p$ $<.06$, for the second- and third-grade cohorts, respectively), $t(633)=1.67, p<.10$, for difference. Within the fifth-grade cohort, a 1.00-standard deviation difference in approval of aggression between children in the fourth grade was predictive of a 0.16-standard deviation difference in aggression in the sixth grade even with the effects of early aggression partialed out. Children whose normative beliefs revealed greater approval of aggression increased in aggression beyond what one would expect from their early aggression. In other words, normative beliefs approving of aggression seem to lead to more aggressive behavior.

In Figure 4 the longitudinal relations between normative beliefs about aggression and aggressive behavior are graphed separately for the youngest (Cohort 2) and oldest (Cohort 5) cohorts. Although the regression analyses reflect only linear effects, these graphs represent the best quadratic functions that fit the longitudinal data. They help clarify the meaning of the regressions.

Looking at the Cohort 2 plot with aggression on the vertical axis (lower left quadrant), one can see that in the youngest cohort, higher initial scores on aggression were predictive of higher later aggression for all levels of normative beliefs, but particularly for children who initially had low beliefs approving of aggression. At the same time, for children who were low on aggression, higher initial scores on normative beliefs predicted

Figure 3 (opposite). Multiple regression analyses relating normative beliefs and peer-nominated aggression over a 3-year span for secondgrade ( $n=317)$, third-grade $(n=323)$, and fifth-grade $(n=375)$ cohorts of children. PRAGG $=$ Peer-Nominated Aggression score; NOBAGS = Total Approval of Aggression score on Normative Beliefs Scale. ${ }^{*} p<.05,{ }^{* *} p<.01,{ }^{* * *} p<.001$. 


\section{COHORT 2}
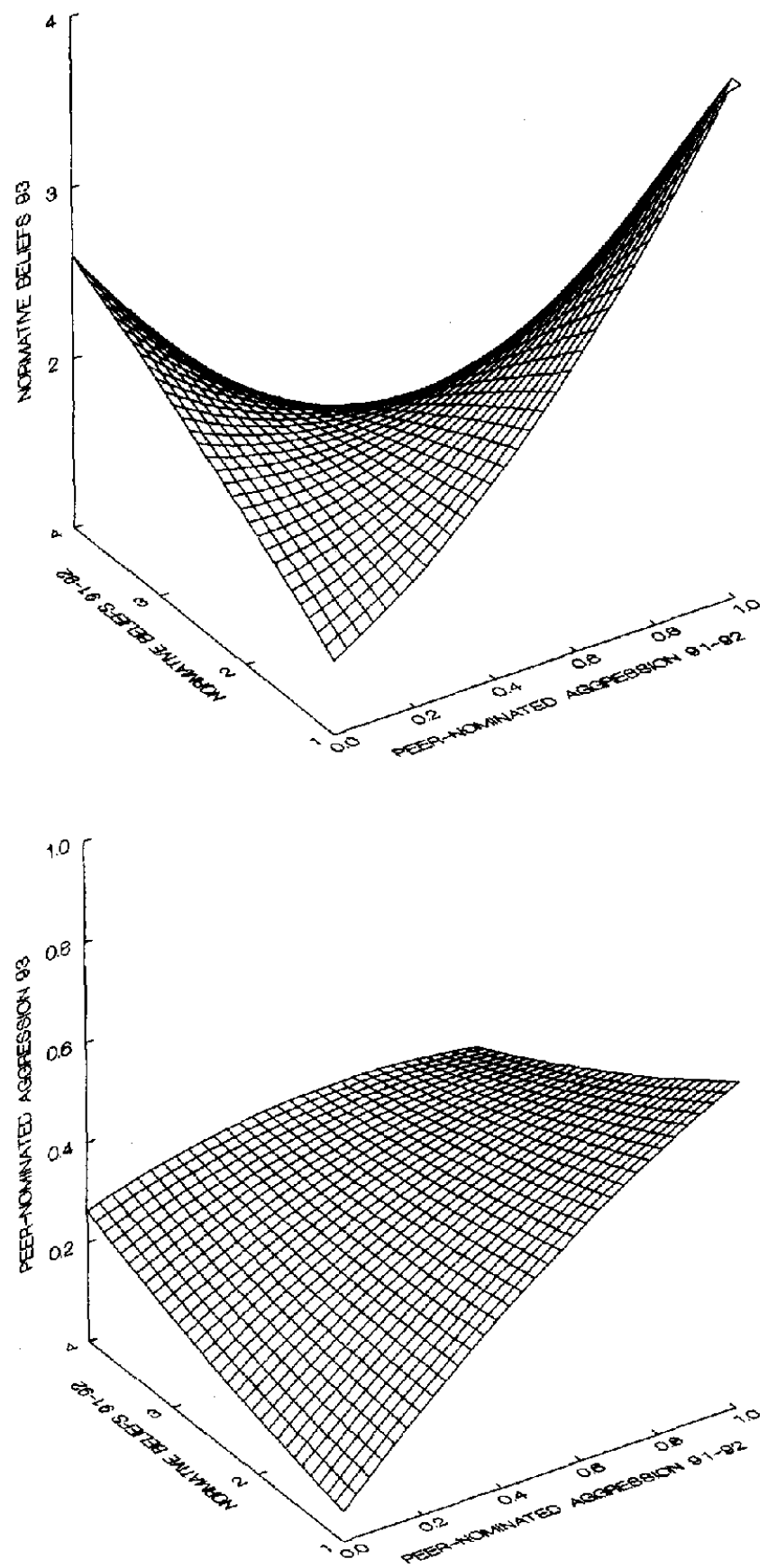

COHORT 5
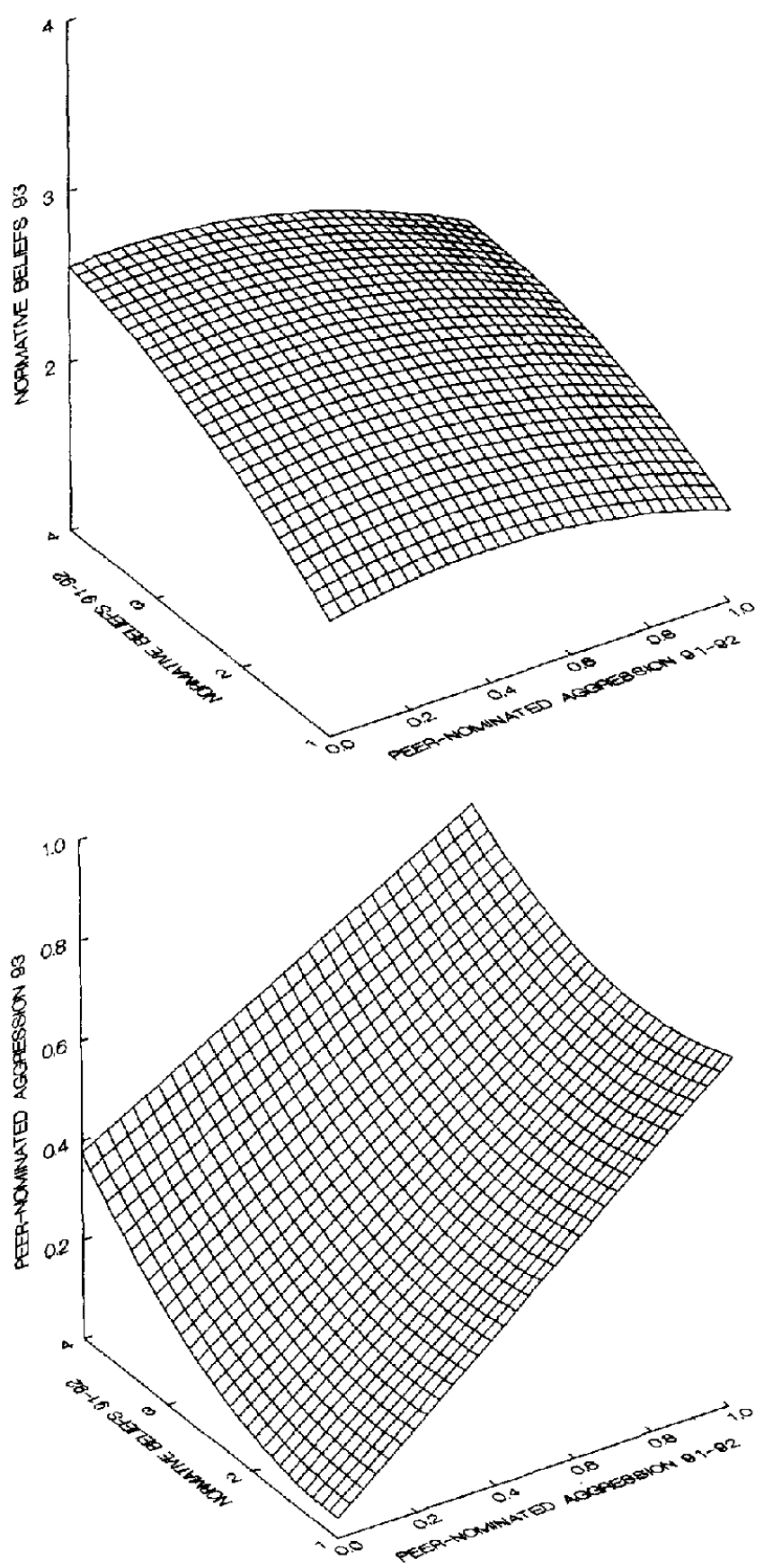

Figure 4. Graphs of best fitting quadratic functions relating Wave 3 aggression or normative beliefs to earlier aggression and normative beliefs for the youngest (Cohort 2 ) and oldest (Cohort 5 ) cohorts.

slightly higher subsequent aggression. The Cohort 2 plot with normative beliefs on the vertical axis presents (upper left quadrant) a more complex picture. For children low to moderate on initial beliefs approving of aggression, engaging in aggressive behavior strongly predicted high later beliefs approving of aggression. However, for children already moderate to high in their approval of aggression, engaging or not engaging in aggressive behavior did not add much to the later prediction of beliefs. 
Again, for children who were low on aggression, normative beliefs did seem to predict subsequent normative beliefs.

The graphs for Cohort 5 are more straightforward. The graph with normative beliefs on the vertical axis (upper right quadrant) shows that for these older children, higher initial normative beliefs approving of aggression were predictive of higher subsequent normative beliefs approving of aggression regardless of initial level of aggressive behavior. For children this old, differences in initial levels of aggressive behavior did not predict differences in later beliefs. The graph with peer-nominated aggression on the vertical axis (lower right quadrant) shows that, as with the younger children, aggression by older children was a strong predictor of subsequent aggression. More important, though, unlike the case with the younger children, higher normative beliefs approving of aggression were highly predictive of higher aggression in these older children. In fact, the quadratic term for normative beliefs in predicting aggression was statistically significant in this model, $t(393)=2.2, p<.03$.

In conjunction, the path analyses in Figure 3 and quadratic models in Figure 4 suggest that aggressive behaving on the part of very young children seems to increase their own approval of aggression, but their approval or lack of approval of aggression does not influence their behavior much. In older children, on the other hand, their behavior no longer seems to influence changes in approval of aggression much, but their normative beliefs about the appropriateness of aggression seem to exert a substantial influence on their aggressive behavior.

\section{General Discussion}

Normative beliefs have been defined as self-regulating beliefs about the appropriateness of social behaviors. They are presumed to be related to perceived social norms but need not necessarily be consistent with those norms. Normative beliefs can be viewed as cognitive abstractions of knowledge acquired through observation, experience, and direct tuition.

In the current research, we derived a short self-report questionnaire to assess a child's normative beliefs about the appropriateness of retaliatory aggression and aggressive behavior in general. We found that these beliefs could be measured reliably with our self-report measure in children as young as first grade regardless of gender or ethnicity. However, children's normative beliefs about aggression appear to be in a great state of flux in the early elementary years. There was virtually no stability in children's beliefs between the first and second grade, with moderate stability becoming apparent by the fourth grade.

Children's normative beliefs about aggression correlated significantly with their actual aggressive behavior, even in the first grade. The correlations with aggressive behavior were not high but were significant both for beliefs about the appropriateness of retaliation and for general beliefs. Furthermore, those who scored in the upper $25 \%$ of children on normative beliefs approving of aggression scored about 0.25 standard deviations higher than average children on aggression. Normative beliefs correlated somewhat higher with a child's aggressive behavior as rated by the child's peers than as rated by the child's teacher, perhaps because teacher ratings tend to be much more skewed (Guerra et al., 1995). There were no significant differences in the correlations across ethnic groups, but the correlations between beliefs and behaviors were significantly higher for boys than for girls. This difference may reflect the fact that the aggression measure assesses both the direct kinds of aggression that are more common in boys and the indirect kinds that are more common in girls, whereas the normative beliefs measure assesses only beliefs about direct aggression.

Both normative beliefs approving of aggression and actual aggressive behavior increase with age during the early elementary years, so the correlations between beliefs and behavior aggregated across grades were higher than the correlations within grades. Approval of aggression showed its largest increase between the first and second grades, suggesting that the socialization processes of the earliest elementary grades may be contributing to children becoming more accepting of aggression. In the high-risk, urban environments represented by the population of children studied, first graders may be learning for the first time many hard lessons about how to behave to survive in a peer culture in which aggression is endemic.

The longitudinal analyses of the different cohorts' development of beliefs and aggression are consistent with such a learning model. We were able to show that individual differences in first and second graders' aggressive behavior were predictive of the individual differences in their normative beliefs about aggression as third graders. This was not true for fourth and fifth graders. Instead, for them, individual differences in their normative beliefs about the appropriateness of aggression predicted how aggressively they behaved as sixth graders. In fact, the best fitting model suggested that aggressive behavior is a quadratically increasing function of normative beliefs approving of aggression for older elementary school children.

This pattern of results is consistent with a developmental learning model in which the early elementary school years are particularly critical for the development of normative beliefs about social behavior. We propose that first graders develop normative beliefs on the basis of their own behavior and how it is reinforced; from observing others' behaviors; and through direct tuition they receive from peers, parents, and others. Thus, their early normative beliefs are unstable, and their early behavior predicts their later beliefs. However, once their beliefs are crystallized, they become resistant to change and thus more stable and less predictable over time from previous behaviors. At that point, their beliefs predict their subsequent behaviors.

What kind of social-cognitive processes in individual children would produce this pattern of results? That a child adopts beliefs consistent with his or her own behavior is not surprising and would be predicted by most theories of cognitive consistency. Of more interest are the processes through which these beliefs, once adopted as normative beliefs, affect subsequent behavior. Although we did not attempt to investigate alternative mechanisms that might be responsible for the influence of normative beliefs about aggression on aggressive behavior, we hypothesized previously that there are at least three ways in which normative beliefs affect children's aggressive behaviors (Guerra, Huesmann, et al., 1994; Huesmann, 1988). First, children's normative beliefs may affect the way in which they perceive the behaviors of others. The more they approve of aggression, the more likely they may be to perceive hostility in others, even if no hostility is present. Second, normative beliefs in support of aggression may cue the retrieval of aggressive scripts for social behavior. Finally, if normative beliefs act as filters to eliminate "inappropriate" behaviors from children's reper- 
toires, the children with more aggressive normative beliefs will be less likely to reject aggressive behaviors once they have thought of them.

Tests of these specific hypotheses must await additional research. However, on the basis of the current findings, it seems fair to conclude that children's normative beliefs about aggressive behavior are influenced by their own early social behaviors, become moderately stable in the early elementary grades, and exert a powerful influence on subsequent social behavior after that time.

\section{References}

Abelson, R. P. (1981). The psychological status of the script concept. American Psychologist, 36, 715-729.

Achenbach, T. M. (1978). The Child Behavior Profile: I. Boys aged 611. Journal of Consulting and Clinical Psychology, 46, 478-488.

Achenbach, T. M. (1991). Integrative guide for the $1991 \mathrm{CBCL} / 4-18$, $Y S R$, and TRF profiles. Burlington: University of Vermont, Department of Psychiatry.

Anderson, E. J. (1990). Streetwise: Race, class, and change in an urban community. Chicago: University of Chicago Press.

Bandura, A. (1986). Social foundations of thought and action: A social cognitive theory. Englewood Cliffs, NJ: Prentice Hall.

Berkowitz, L. (1988). Frustrations, appraisals, and aversively stimulated aggression. Aggressive Behavior, 14, 3-12.

Berkowitz, L. (1993). Pain and aggression: Some findings and implications [Special issue]. Motivation and Emotion, 17, 277-293.

Bjorkqvist, K., Lagerspetz, K. M. J., \& Kaukiainen, A. (1992). Do girls manipulate and boys fight? Developmental trends regarding direct and indirect aggression. Aggressive Behavior, 18, 117-128.

Caspi, A., Elder, G., \& Bem, D. (1987). Moving against the world: Life course patterns of explosive children. Developmental Psychology, 23, 308-314.

Crick, N. R., \& Dodge, K. A. (1994). A review and reformulation of social information processing mechanisms in children's adjustment. Psychological Bulletin, 115, 74-101.

Crick, N. R., \& Grotpeter, J. K. (1995), Relational aggression, gender, and social-psychological adjustment. Child Development, 66, 710722.

Dodge, K. A. (1980). Social cognition and children's aggressive behavior. Child Development, 53, 620-635.

Dodge, K. A. (1986). A social information processing model of social competence in children. In M. Perlmutter (Ed.), Minnesota Symposium on Child Psychology (pp. 77-125). Hillsdale, NJ: Erlbaum.

Dodge, K. A. (1993). Social-cognitive mechanisms in the development of conduct disorder and depression. Annual Review of Psychology, 44, 559-584.

Eron, L. D. (1987). The development of aggressive behavior from the perspective of a developing behaviorist. American Psychologist, 42, $435-442$.

Eron, L. D., \& Huesmann, L. R. (1990). The stability of aggressive behavior - even into the third generation. In M. Lewis \& S. M. Miller (Eds.), Handbook of Developmental Psychopathology (pp. 147156). New York: Plenum.

Eron, L. D., Walder, L. O., \& Lefkowitz, M. M. (1972). The learning of aggression in children. Boston: Little, Brown.

Farrington, D. P. (1990). Childhood aggression and adult violence: Early precursors and later-life outcomes. In D. J. Pepler \& K. H. Rubin (Eds.), The development of childhood aggression (pp. 5-30). Hillsdale, NJ: Erlbaum.

Fingerhut, L. A., \& Kleinman, J. D. (1990). International and interstate comparisons of homicide among young males. Journal of the American Medical Association, 263, 3292-3295.
Fishbein, M., \& Ajzen, I. (1975). Belief, attitude, intention, and behavior. Reading, MA: Addison-Wesley.

Fiske, S. T., \& Taylor, S. E. (1991). Social cognition. New York: McGraw-Hill.

Geen, R. (1990). Human aggression. Pacific Grove, CA: Brooks/Cole.

Guerra, N. G., Huesmann, L. R, \& Hanish, L. (1994). The role of normative beliefs in children's social behavior. In N. Eisenberg (Ed.), Review of personality and social psychology, development and social psychology: The interface (pp. 140-158). London: Sage.

Guerra, N. G., Huesmann, L. R., Tolan, P., Van Acker, R., \& Eron, L. D. (1995). Stressful events and individual beliefs as correlates of economic disadvantage and aggression among urban children. Journal of Consulting and Clinical Psychology, 63, 518-528.

Guerra, N. G., Nucci, L., \& Huesmann, L. R. (1994). Moral cognition and childhood aggression. In L. R. Huesmann (Ed.), Aggressive behavior: Current perspectives (pp. 13-33). New York: Plenum.

Guerra, N. G., \& Slaby, R. G. (1990). Cognitive mediators of aggression in adolescent offenders: II. Intervention. Developmental Psychology, $26,269-277$

Hammond, W. R., \& Yung, B. R. (1991). Preventing violence in at-risk African-American youth. Journal of Health Care for the Poor and Underserved, 2, 1-16.

Holmberg, M. (1980). The development of social interchange patterns from 12-42 months. Child Development, 51, 448-456.

Huesmann, L. R. (1982). Television violence and aggressive behavior. In D. Pearl, L. Bouthilet, \& J. Lazar (Eds.), Television and behavior: Ten yeurs of scientific programs and implications for the 80's (pp. 126-137). Washington, DC: U.S. Government Printing Office.

Huesmann, L. R. (1988). An information-processing model for the development of aggression. Aggressive Behavior, 14, 13-24.

Huesmann, L. R. (1994), Aggressive behavior: Current perspectives. New York: Plenum.

Huesmann, L. R., \& Eron, L. D. (1984). Cognitive processes and the persistence of aggressive behavior. Aggressive Behavior, 10, 243-251.

Huesmann, L. R., \& Eron, L. D. (Eds.). (1986). Television and the aggressive child: A cross-national comparison. Hillsdale, NJ: Erlbaum.

Huesmann, L. R., \& Eron, L. D. (1989). Individual differences and the trait of aggression. European Journal of Personality, 3, 95-106.

Huesmann, L. R., \& Eron, L. D. (1992). Childhood aggression and adult criminality. In J. McCord (Ed.), Advances in criminological theory: Crime facts, fictions, and theory (pp. 157-192). New Brunswick, NJ: Transaction Publishers.

Huesmann, L. R., Eron, L. D., Lefkowitz, M. M., \& Walder, L. O. (1984). The stability of aggression over time and generations. Developmental Psychology, 20,1120-1134.

Huesmann, L. R., Guerra, N. G., Miller, L., \& Zelli, A. (1992). The role of social norms in the development of aggression. In H. Zumkley \& A. Fraczek (Eds.), Socialization and aggression (pp. 139-151). New York: Springer-Verlag.

Huesmann, L. R., Guerra, N. G., Zelli, A., \& Miller, L. (1992). Differing normative beliefs about aggression for boys and girls. In K. Bjorkquist \& P. Niemela (Eds.), Of mice and women: Aspects of female aggression. San Diego, CA: Academic Press.

Kagen, J. (1988). Temperamental contributions to social behavior. American Psychologist, 44, 668-674.

Loeber, R., \& Dishion, T. ( 1983). Early predictors of male delinquency: A review. Psychological Bulletin, 94, 68-99.

Magnusson, D., Duner, A., \& Zetterblom, G. (1975). Adjustment: A longitudinal study. Stockholm: Almqvist \& Wiksell.

Moffitt, T. E. (1990). Juvenile delinquency and attention-deficit disorder: Developmental trajectories from age 3 to 15 . Child Development, 61, $893-910$.

Moffitt, T. E. (1993). Adolescence-limited and life-course-persistent antisocial behavior: A developmental taxonomy. Psychological Review, $100,674-701$. 
Olweus, D. (1979). The stability of aggressive reaction patterns in human males: A review. Psychological Bulletin, 85, 852-875.

Robins, L. N., \& Ratcliff, K. S. (1980). Childhood conduct disorders and later arrest. In L. N. Robins, P. J. Clayton, \& J. K. Wing (Eds.), The social consequences of psychiatric illness (pp. 248-263). New York: Brunner/Mazel.

Rosenthal, R. (1986). The social consequences of small effects. Journal of Social Issues, 42, 141-154.

Rumelhart, D. E., \& Ortony, A. (1977). The representation of knowl- edge in memory. In R. C. Anderson, R. J. Spiro, \& W. E. Montague (Eds.), Schooling and the acquisition of knowledge. Hillsdale, NJ: Erlbaum.

Schneider, W., \& Shiffrin, R. (1977). Controlled and automatic human information processing: Detection, search, and attention. Psychological Review, 84, 1-66.

Slaby, R. G., \& Guerra, N. G. (1988). Cognitive mediators of aggression in adolescent offenders: I. Assessment. Developmental Psychology, $24,580-588$.

\section{Appendix}

The 20 Items on the Normative Beliefs About Aggression Scale

\section{Response Choices}

\section{IT'S PERFECTLY OK}

IT'S SORT OF OK

IT'S SORT OF WRONG

IT'S REALLY WRONG

The choices are ordered to agree with the framing of the question; so "REALLY WRONG"' is the first alternative for WRONG questions and "PERFECTLY OK" is the first alternative for OK questions.

\section{Instructions}

The following questions ask you about whether you think certain behaviors are WRONG or are OK. Circle the answer that best describes what you think. Circle ONE and only one answer.

\section{Retaliation Belief Questions}

Suppose a boy says something bad to another boy, John

1) Do you think it's OK for John to scream at him?

2) Do you think it's OK for John to hit him?

Suppose a boy says something bad to a girl.

3 ) Do you think it's wrong for the girl to scream at him?

4) Do you think it's wrong for the girl to hit him?

Suppose a girl says something bad to another girl, Mary.

5) Do you think it's OK for Mary to scream at her?

6) Do you think it's OK for Mary to hit her?
Suppose a girl says something bad to a boy.

7) Do you think it's wrong for the boy to scream at her?

8) Do you think it's wrong for the boy to hit her?

Suppose a boy hits another boy, John?

9) Do you think it's wrong for John to hit him back?

Suppose a boy hits a girl.

10) Do you think it's OK for the girl to hit him back?

Suppose a girl hits another girl, Mary?

11) Do you think it's wrong for Mary to hit her back?

Suppose a girl hits a boy.

12) Do you think it's wrong for the boy to hit her back?

\section{General Belief Questions}

13. In general, it is wrong to hit other people.

14. If you're angry, it is OK to say mean things to other people.

15. In general, it is OK to yell at others and say bad things.

16. It is usually OK to push or shove other people around if you're mad.

17. It is wrong to insult other people.

18. It is wrong to take it out on others by saying mean things when you're mad.

19. It is generally wrong to get into physical fights with others.

20. In general, it is OK to take your anger out on others by using physical force.

Received October 31, 1994

Revision received February 6, 1996

Accepted February 17, 1996 